\title{
Progresos en la preparación de nanopartículas magnéticas multifuncionales para aplicación en la medicina
}

\section{Progress in the preparation of magnetic nanoparticles for applications in medicine}

\author{
Jorge Luis López Aguilar ${ }^{1}$, José Higino Dias Filho², Roberto Paniago ${ }^{3}$, Hans D.- Pfannes ${ }^{3}$, Karla Balzuweit ${ }^{3}$ \\ ${ }^{1}$ Universidad Federal de Acre, Ciências Biológicas e da Natureza, Rio Branco, Brasil \\ ${ }^{2}$ Universidad Estadual de Montes Claros, Departamento de Ciências Exatas, Montes Claros, MG, Brasil \\ ${ }^{3}$ Universidad Federal de Minas Gerais, Departamento de Física, Belo Horizonte, MG, Brasil
}

DOI: https://doi.org/10.33017/RevECIPeru2013.0014/

\section{Resumen}

En este trabajo hacemos una revisión de tres rutas de síntesis de nanopartículas de magnetita $\left(\mathrm{Fe}_{3} \mathrm{O}_{4}\right)$ funcionalizadas que pueden utilizarse para transportar fármacos. Este tipo de partículas no tóxicas, son sin duda, uno de los grandes responsables por el avance en el tratamiento médico contra tumores, entrega dirigida de fármacos, inmovilización de enzimas, purificación de RNA y DNA, diagnostico de enfermedades usando imagen por resonancia magnética, marcación de células-madre, etc. Para su aplicación las partículas deben ser recubiertas con un material biológicamente activo. En este sentido fueron sintetizadas Nanopartículas de magnetita por el método de coprecipitación química usando diversas soluciones químicas acuosas de $\mathrm{FeCl}_{2} .4 \mathrm{H}_{2} \mathrm{O}, \mathrm{FeCl}_{3} .6 \mathrm{H}_{2} \mathrm{O}$ e $\mathrm{FeSO}_{4} .7 \mathrm{H}_{2} \mathrm{O}$ mezclándolas en determinadas proporciones. Esa mezcla fue precipitada con soluciones de $\mathrm{NaOH}$ y NH $\mathrm{NH}_{4} \mathrm{OH}$. La superficie fue tratada con una solución acuosa de $\mathrm{Fe}\left(\mathrm{NO}_{3}\right)_{3} .9 \mathrm{H}_{2} \mathrm{O}$ para obtener Nanopartículas de magnetita con doble capa eléctrica. La funcionalización fue realizada con acido oleico puro, otro con ácidos grasos obtenidos de aceites vegetales, otra recubierta con quitosano y oro. Otra preparación de $\mathrm{Fe}_{3} \mathrm{O}_{4}$ fue realizada disolviendo $\mathrm{FeCl}_{3}$ y $\mathrm{Na}_{2} \mathrm{SO}_{3}$ en agua para formar una solución e después fue agregado acido oleico como surfactante. Esta solución fue precipitada con $\mathrm{NaOH}$. Las Nanopartículas obtenidas fueron de un diámetro de la partícula de 5, 7 y 10nm como fue observado por microscopia electrónica de transmisión y difracción de rayos-X. Las propiedades magnéticas fueron estudiadas por espectroscopia Mössbauer y medidas de magnetización en el rango de 4.2- 300K. La magnetización de saturación $\left(\mathrm{M}_{\mathrm{s}}\right)$ fue de 3, 4 y $5.5 \mathrm{emu} / \mathrm{g}$ en las muestras y sus coercividades de 30, 80 y 150 Oe. El valor de magnetización de saturación bajo fue atribuido a la no colinearidad de los espines en la superficie de las partículas. De las medidas de magnetización la constante de energía de anisotropía magnética $(\mathrm{K})$ fue obtenida con valores de $1.6 \times 10^{4}, 2 \times 10^{4}$ y $2.3 \times 10^{4} \mathrm{~J} / \mathrm{m}^{3}$ para las muestras. Los espectros de $\mathrm{Fe}_{3} \mathrm{O}_{4}$ a la temperatura ambiente mostraron una línea debido a la relajación superparamagnetica y dos sextetos a temperatura baja. La forma de la línea en los espectros Mössbauer varían con las temperaturas y fueron simulados usando un modelo de dos niveles (espin 1/2) de relajación superparamagnetica y teoría estocástica. Se tuvo en cuenta que una distribución del tamaño de las partículas que obedecen una distribución log-normal. Las partículas fueron usadas para cargar fármacos obtenidos de extractos de plantas de la amazonia con propiedades antitumorales y antiinflamatorios.

Descriptores: Nanopartículas, magnetita, fármaco

\section{Abstract}


In this paper we review three routes of synthesis of nanoparticles of magnetite $\left(\mathrm{Fe}_{3} \mathrm{O}_{4}\right)$ functionalized to be used to transport drugs. These non- toxic particles, are undoubtedly one of the major responsible for the advance in medical treatment against tumors, targeted drug delivery, immobilization of enzymes, RNA and DNA purification, disease diagnosis using magnetic resonance imaging, dial stem cells, etc. For application the particles must be coated with a biologically active material. Thus magnetite nanoparticles were synthesized by chemical coprecipitation method using various aqueous chemical solutions of $\mathrm{FeCl}_{2} .4 \mathrm{H}_{2} \mathrm{O}, \mathrm{FeCl}_{3} .6 \mathrm{H}_{2} \mathrm{O}$ and $\mathrm{FeSO}_{4} .7 \mathrm{H}_{2} \mathrm{O}$ mixing in certain proportions. These mixtures were precipitated with $\mathrm{NaOH}$ and $\mathrm{NH}_{4} \mathrm{OH}$. The surface was treated with an aqueous solution of $\mathrm{Fe}\left(\mathrm{NO}_{3}\right)_{3} .9 \mathrm{H}_{2} \mathrm{O}$ to obtain magnetite nanoparticles with electric double layer. The functionalization was carried out with pure oleic acid, other fatty acids derived from vegetable oils, and other chitosan -coated gold. Another preparation was made by dissolving $\mathrm{Fe}_{3} \mathrm{O}_{4}, \mathrm{FeCl}_{3}$ and $\mathrm{Na}_{2} \mathrm{SO}_{3}$ in water to form a solution and then oleic acid was added as a surfactant. This solution was precipitated with $\mathrm{NaOH}$. The obtained nanoparticles were of a particle diameter of 5, 7 and $10 \mathrm{~nm}$ as observed by transmission electron microscopy and $X$ - ray diffraction. The magnetic properties were studied by Mossbauer spectroscopy and magnetization measurements in the range of $4.2-250 \mathrm{~K}$. The saturation magnetization (Ms) was 3, 4 and $5.5 \mathrm{emu} / \mathrm{g}$ in the samples and coercivities of 30, 80 and 150 Oe. The low value of saturation magnetization was attributed to non- colinearity of the spins at the surface of the particles. Magnetization measurements of the constant magnetic anisotropy energy $(\mathrm{K})$ was obtained with values of $1.6 \times 10^{4}, 2 \times 10^{4}$ and $2.3 \times 10^{4} \mathrm{~J} / \mathrm{m}^{3}$ for the samples. $\mathrm{Fe}_{3} \mathrm{O}_{4}$ spectra at room temperature showed a line due to the superparamagnetic relaxation and two sextets at low temperature. The shape of the line in Mössbauer spectra vary with temperature and were simulated using a two-level model (spin 1/2) of superparamagnetic relaxation and stochastic theory. He took into account that the size distribution of the particles obeys a lognormal distribution. The particles were used to carry drugs obtained from plant extracts from the Amazon with antitumor and anti-inflammatory properties

\section{Keywords: Nanoparticles, magnetite,}

\section{Introducción}

En la última década el desenvolvimiento de nanopartículas magnéticas funcionalizadas de óxidos de ferro como la magnetita $\left(\mathrm{Fe}_{3} \mathrm{O}_{4}\right)$ aplicada en la biología y en la medicina es, sin duda, uno de los grandes responsables por el avance en el tratamiento antitumoral por hipertermia magnética, entrega dirigida de fármacos, inmovilización de enzimas, purificación de RNA y DNA, diagnostico de enfermedades usando imagen por resonancia magnética, marcación de células-madre, etc. [1-3]. Para el empleo en el área biomédica, las nanopartículas magnéticas deben atravesar la barrera endotelial y acumularse específicamente en las células-blanco, sin daño a las células sanas. Estas características pueden ser alcanzadas por medio de un tratamiento superficial de las partículas con un material biológicamente activo, con un control de sus parámetros físicos, tales como el tamaño de la partícula, la susceptibilidad magnética de la solución y el conocimiento de su comportamiento en el organismo. Para su aplicación biomédica las partículas deben ser del tipo núcleo-corona (core/Shell), tener alta saturación magnética y biocompatibilidad de la superficie de la nanopartícula con el ambiente biológico. Estudios "in vivo" han demostrado que las nanopartículas de $\mathrm{Fe}_{3} \mathrm{O}_{4}$ son relativamente seguras, ya que no se acumulan en los órganos vitales y son rápidamente eliminados del cuerpo [4]. Existen varias variables que influencian la síntesis de las nanopartículas por el método de coprecipitación química, como a velocidad de la mezcla de los reactivos químicos, $\mathrm{pH}$ de la solución, temperatura de preparación, tiempo usado en la mezcla de las soluciones, agitación magnética, centrifugación, funcionalización con moléculas orgánicas y ligandos, etc [5]. El estudio de esas variables va posibilitar la preparación de nanoestruturas con propiedades magnéticas bien especificas muy diferentes de las tradicionales, cuya comprensión microscópica exige un conocimiento detallado de la preparación, por lo que es necesario conocer la relación superficie-volumen (núcleocorona), tamaño finito de las partículas, las interacciones entre las partículas, etc. Una de las aplicaciones de nanopartículas dirigibles funcionalizadas con compuestos orgánicos para uso en la medicina es la vectorización de fármacos, que pueden ser obtenidos de los extractos preparados de las plantas de la Amazonia, para órganos específicos que es muy complejo debido a la necesidad del cargador desempeñar simultáneamente diferentes funciones. Primeramente, las nanopartículas deben ser capaces de conducir una cantidad significativa de fármacos y promover su liberación con un perfil cinético adecuado. Una segunda fase, después de la administración del fármaco debe ser capaz de impactar el blanco de manera específica y 
subsecuentemente liberar el fármaco. Por otro lado, la funcionalización puede alterar las interacciones de las nanopartículas con las células blanco en términos de su eficiencia, de su adhesión e internalización. En estos casos es muy importante mejorar la biocompatibilidad, resistir a la adsorción de las proteínas y aumentar el tiempo de circulación de las nanopartículas en el organismo, por eso es necesario trabajar con diferentes ligandos que sean adecuados para el transporte de fármacos. Un ligando que puede ser complejado con $\mathrm{Fe}_{3} \mathrm{O}_{4}$ es el quitosano que es un polisacárido que posee sitios catiónicos (grupos amina) que pueden actuar bien en la complexación química estable de los cationes metálicos de los metales de transición como el hierro. Esas nanoestruturas del tipo núcleo/corona magnética son de gran interés del punto de vista tecnológico, en las aplicaciones medicas porque es en esas nanoestruturas que pueden ser incorporadas fármacos, proteínas, anticuerpos, visualizando el tratamiento de enfermedades. Existen pocos grupos en condiciones de sintetizar y funcionalizar nanopartículas con propiedades magnéticas específicas y con posibilidades de aplicación direccionada al sector de la medicina con aplicación antitumoral. En este trabajo mostramos el desenvolvimiento de nanoestructuras del tipo núcleo-corona constituidos por nanopartículas de magnetita funcionalizadas con ácidos grasos obtenidos de los aceites de Mauritia flexuosa $L$. y Copaifera officinalis L., recubiertas con quitosano cargando un fármaco obtenido del extracto de la planta Piper regnelli (Miq.) para ser utilizado en la entrega dirigida de un fármaco antitumoral.

\section{Síntesis de Nanopartículas magnéticas y funcionalización}

La síntesis de las nanopartículas magnéticas de magnetita fue realizada por el proceso de coprecipitación química en medio acuoso con algunas modificaciones, cambiando las condiciones de preparación como la temperatura, $\mathrm{pH}$ de la solución, velocidad de agitación y tipo de surfactante usado. En el primer método la magnetita $\left(\mathrm{Fe}_{3} \mathrm{O}_{4}\right)$ fue preparada en un reactor cerrado en ambiente de nitrógeno adicionando $0.52 \mathrm{~g}$ de $\mathrm{FeCl}_{2} .4 \mathrm{H}_{2} \mathrm{O}$ y $3 \mathrm{ml}$ de $\mathrm{HCl}$ en una solución acuosa de $160 \mathrm{ml}$ de $\mathrm{FeCl}_{3} .6 \mathrm{H}_{2} \mathrm{O}(0.035 \mathrm{M})$ en temperatura ambiente y agitación rápida. La precipitación fue realizada en usando una solución acuosa de $\mathrm{NaOH}(4.125 \mathrm{M})$ y agitación rápida. El precipitado de magnetita fue separado del agua usando un imán y lavado con agua destilada varias veces hasta un $\mathrm{pH}$ neutro y después centrifugado durante $5 \mathrm{~min}$ a $7000 \mathrm{rpm}$ para la homogenización de las partículas. La muestra centrifugada fue acidificada con una solución de $\mathrm{HNO}_{3}(2 \mathrm{M})$ durante $2 \mathrm{hrs}$. y posterior tratamiento con una solución acuosa de $\mathrm{Fe}\left(\mathrm{NO}_{3}\right)_{3}$ (1M) para conseguir la estabilidad de las partículas y así poder ser dispersados en agua transformándose en un ferrofluido de magnetita con carga eléctrica superficial. En el segundo método la magnetita fue preparada mezclando $0.85 \mathrm{gr}$. de $\mathrm{Na}_{2} \mathrm{SO}_{3}$ en una solución acuosa de $\mathrm{FeCl}_{3} .6 \mathrm{H}_{2} \mathrm{O}(0.37 \mathrm{M})$. La mezcla fue calentada a $50^{\circ} \mathrm{C}$ y durante el calentamiento es adicionado $1.5 \mathrm{ml}$ de ácido oleico como surfactante. La precipitación fue realizada usando una solución de $\mathrm{Na}(\mathrm{OH})(0.8 \mathrm{M})$. El precipitado fue calentado a $80^{\circ} \mathrm{C}$ durante $1 \mathrm{~h}$ en agitación rápida. Posteriormente el precipitado fue lavado varias veces con agua destilada e etanol. En el tercer método la magnetita fue preparad mezclando soluciones acuosas de $\mathrm{FeCl}_{3} .6 \mathrm{H}_{2} \mathrm{O}(0.5 \mathrm{M})$ y $\mathrm{FeSO}_{4} .7 \mathrm{H}_{2} \mathrm{O}(0.5 \mathrm{M})$ en la relación de 3:2 en temperatura ambiente y agitación rápida. La precipitación fue realizada usando una solución acuosa de $\mathrm{Na}(\mathrm{OH})(1 \mathrm{M})$ y acidificando el precipitado con $\mathrm{HCl}$ y agitación durante $30 \mathrm{~min}$. El precipitado fue lavado varias veces hasta un $\mathrm{pH}$ neutro. Para funcionalizar las partículas procedemos al recubrimiento de $\mathrm{Fe}_{3} \mathrm{O}_{4}$ que puede ser realizado dispersando esas partículas en una mezcla de quitosano con acido acético $(2 \%, v / v)$ y agitación rápida usando un sistema de ultrasonido (sonicador) para una mejor homogenización y distribución de las partículas. Los ácidos grasos que fueron usados en la funcionalización de las Nanopartículas magnéticas fueron obtenidos de los aceites de Mauritia flexuosa L. y Copaifera longsdorfii. Inicialmente para obtener estos ácidos grasos los aceites fueron tratados con una solución acuosa de $\mathrm{NaOH}(30 \%$, w/v) para la saponificación y fueron mantenidos en baño maría durante $5 \mathrm{hrs}$. Después de ese período fue formada glicerina que fue removida usando una solución acuosa de $\mathrm{NaCl}$ y lavado con agua destilada. Los precipitados de ácidos grasos fueron acidificados con una solución de $\mathrm{HCl}(3 \mathrm{M})$ por algunas horas y posteriormente lavados con diclorometano y sulfato de sodio para concentración de los ácidos grasos de interés y posterior purificación (Fig 1).

Las nanoparticulas de magnetita fueron mantenidos en suspensión en agua a una temperatura de $70 \mathrm{oC}$ y sobre una agitación moderada fueron mezcladas con los ácidos grasos para obtener Nanopartículas funcionalizadas con ácidos grasos. Los fármacos pueden ser obtenidos de los extractos preparados de plantas medicinales. Los extractos hidro alcohólicos fueron preparados utilizando $150 \mathrm{~g}$ de hojas de la planta Piper regnellii usando el proceso de extracción de los principios activos a través de la técnica de maceración y percolación con 1200 ml de 
solución etanol/agua $70 \%$. Después de un período de 63 horas de maceración, El contenido fue percolado dando $750 \mathrm{ml}$ de extracto hidroalcohólico de las hojas, el cual fue secado hasta obtener un gel de principios activos. Las nanopartículas de magnetita con ácidos grasos y quitosano fueron ligados con el gel del extracto obtenido de Piper regnellii por sonicación y después $30 \mathrm{~min}$. las nanopartículas se dispersaron en la fase acuosa. La suspensión coloidal acuosa fue centrifugada a $5000 \mathrm{rpm}$ por 5 minutos y encapsulada transformándose en un fármaco. La caracterización estructural e magnética de las muestras fue realizada usando las técnicas de microscopia electrónica de transmisión (MET), difracción de rayos- $X$, medidas magnéticas y espectroscopia Mössbauer.

OBTENCEON DE ÁCIDOS GRASOS DE ACETTES VEGETALES

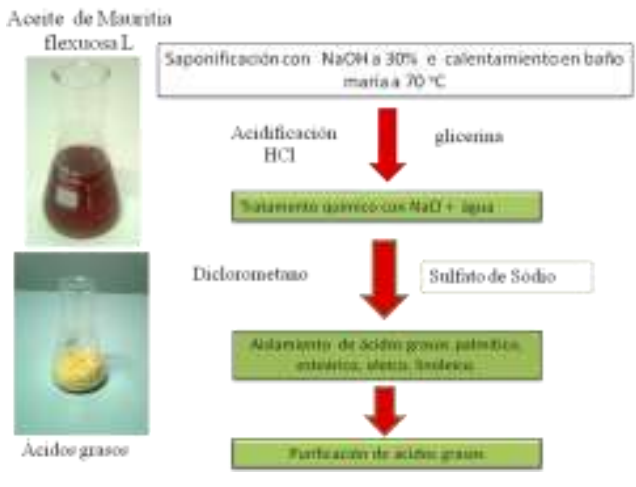

Figura 1: Esquema de obtención de ácidos grasos.

\section{Resultados y discusión}

Es conocido que el método de preparación de las nanopartículas influencia la morfología y las propiedades estructurales y magnéticas de esas nanopartículas para ser aplicado de forma específica. En la Figura 2 observamos un esquema de una nanopartícula de magnetita cuya superficie puede ser modificada para cargar un medicamento o droga, molécula activa, agregar un agente de contraste de imagen o recubrir con un polímero como el polietilenoglicol (PEG).

La relación de átomos de $\mathrm{Fe}$ e $\mathrm{O}$ de las Nanopartículas sintetizadas analizado con la técnica de Espectroscopia por energía dispersiva (EDS) dio un valor de 2.85:3.92, el cual es próximo de la formula estequiométrica de $\mathrm{Fe}_{3} \mathrm{O}_{4}$ pura. La ecuación química que representa la formación de magnetita $\left(\mathrm{Fe}_{3} \mathrm{O}_{4}\right)$ por el método de coprecipitación química adoptado en este trabajo puede ser expresado por: $\mathrm{FeCl}_{2}+2 \mathrm{FeCl}_{3}+8 \mathrm{Na}(\mathrm{OH}) \leftrightarrow \mathrm{Fe}_{3} \mathrm{O}_{4}+4 \mathrm{H}_{2} \mathrm{O}$. Las imágenes de las nanopartículas de magnetita puras y funcionalizadas observadas MET mostro que la distribución de las partículas es esférica y no muestran aglomeración indicando que las técnicas de preparación fueron adecuadas como puede observarse en la figura 3.

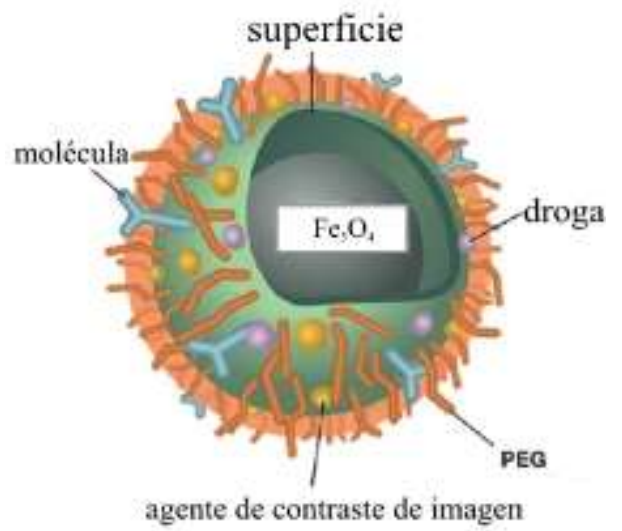

Figura 2: Esquema de una nanopartícula de magnetita cuya superficie fue modificada.

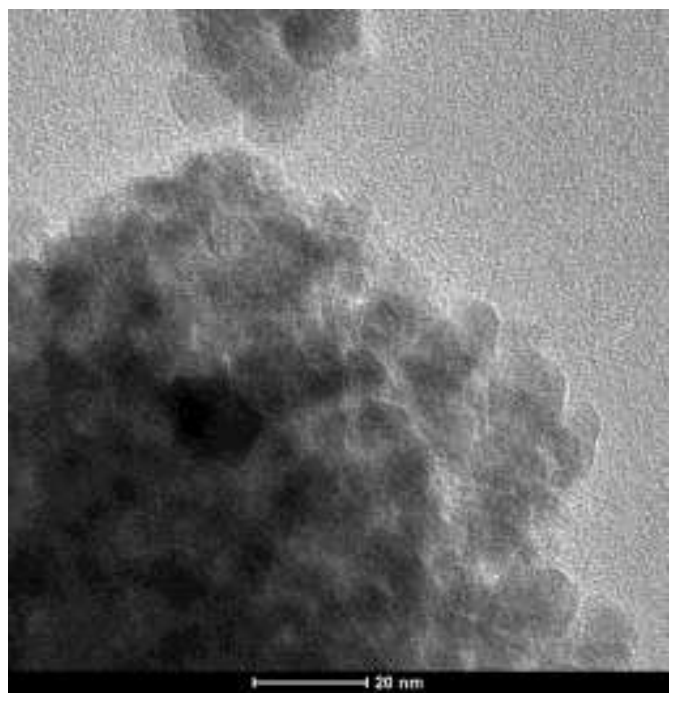

Figura 3: Imagen MET de nanopartículas de $\mathrm{Fe}_{3} \mathrm{O}_{4}$ preparado con el primer método.

Otra imagen MET de nanopartículas de $\mathrm{Fe}_{3} \mathrm{O}_{4}$ preparada por el segundo método y funcionalizado con ácidos grasos del aceite de Mauritia flexuosa $L$. puede observarse en la figura 4. El ácido oleico usado como surfactante evita la aglomeración de las partículas.

En la figura 5 puede ser observado la imagen MET de nanoparticulas sintetizado por el tercer método 
recubierta con oro y funcionalizado con ácidos grasos obtenido de Mauritia flexuosa $L$.

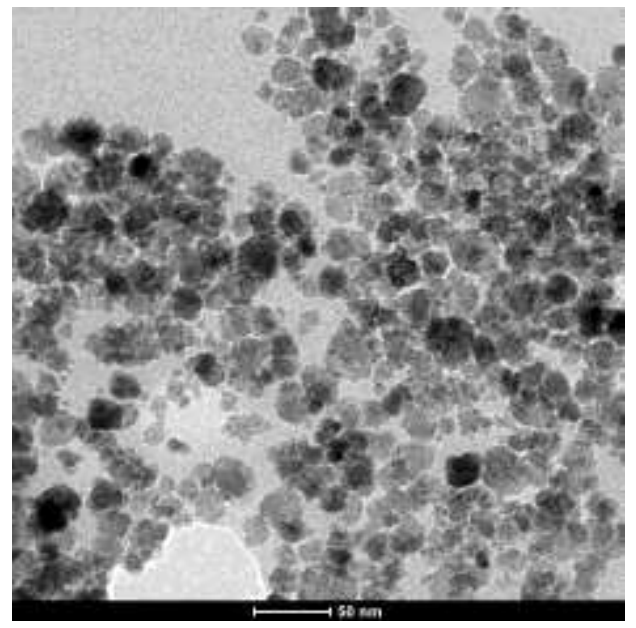

Figura 4: Imagen MET de nanopartículas de $\mathrm{Fe}_{3} \mathrm{O}_{4}$ preparado con el segundo método funcionalizado con ácidos grasos del aceite de Mauritia flexuosa $L$.

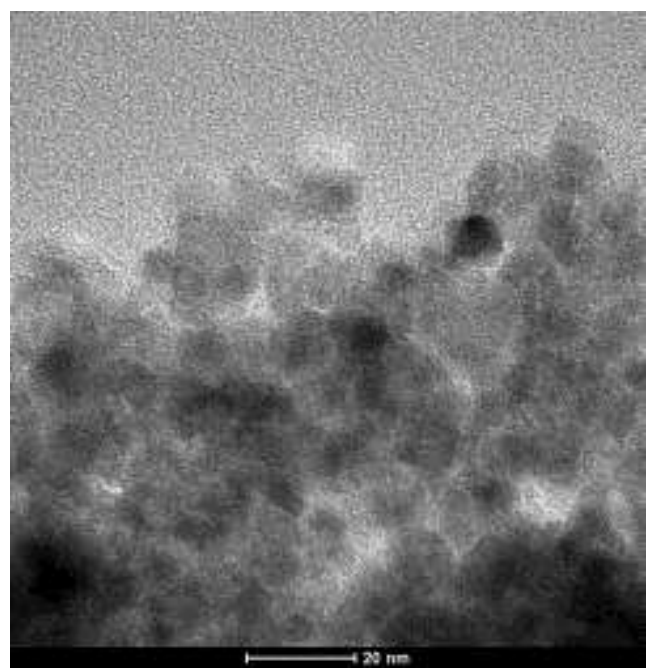

Figura 5: Imagen MET de nanopartículas de $\mathrm{Fe}_{3} \mathrm{O}_{4}$ preparado con el tercer método recubierto con oro funcionalizado con ácidos grasos de Mauritia flexuosa $L$.

La determinación de la estructura de las muestras realizada con un difractometro de rayos-X (Rigaku Gigerflex, Tubo de $\mathrm{Cu} \mathrm{K}$ ). La estructura Fd3m obtenida en todas las muestras fue cúbica tipo espinela que corresponde al patrón de $\mathrm{Fe}_{3} \mathrm{O}_{4}$. El patrón de difracción de las muestras de magnetita funcionalizadas con ácidos grasos obtenidos de los aceites vegetales no mostro diferencias en relación a las muestras puras de magnetita indicando que la estructura se mantiene constante después de la funcionalización como puede ser observado en la figura 6. En esta figura se observan los difractogramas de rayos- $X$ de la magnetita pura sintetizados por los 3 métodos (Figs. $6 a, 6 b$ y $6 c$ ) y funcionalizados con los acidos grasos del aceite de Mauritia flexuosa L. y Copaifera longsdorfii. Las líneas son anchas mostrando un aumento do tamaño de las partículas para $D_{X R D}=(5,7$ y 10$) \mathrm{nm}$. El parámetro de red a calculada del patrón de difracción fue de $\mathbf{a}=(8.44 \pm 0.01) \AA$ para la muestra pura de magnetita y $\mathbf{a}=(8.45 \pm 0.01) \AA$ para la muestra recubierta con quitosano y funcionalizado con ácidos grasos. El valor del parámetro de red para la magnetita pura está de acuerdo con los valores reportados en la literatura (JCPDS-ICDD $\left.\mathrm{Fe}_{3} \mathrm{O}_{4} \# 22-1083,1997\right)$. De los difragtogramas de rayos-X podemos afirmar que no hay evidencias de impurezas en todas las muestras analizadas.

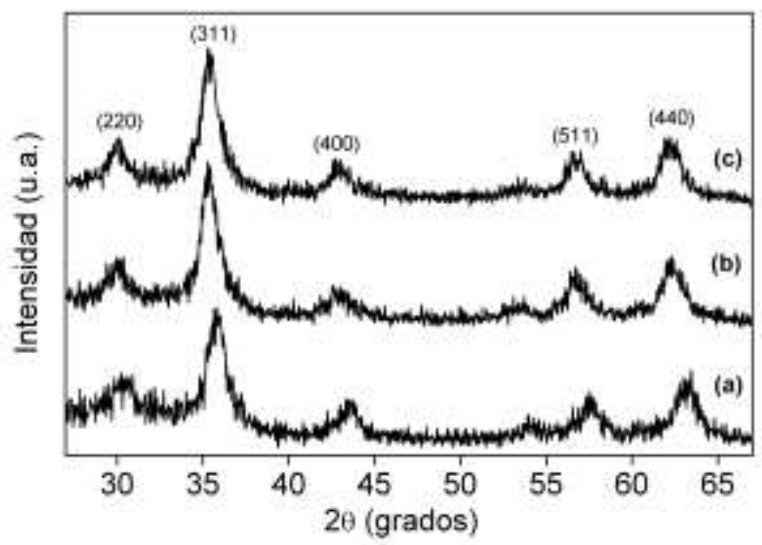

Figura 6: Difractogramas de rayos- $X$ de la magnetita a)pura e funcionalizada con ácidos grasos de b) Mauritia flexuosa L. c) Copaifera longsdorfii.

Otra técnica usada para la caracterización estructural y magnética de nuestras muestras fue la espectroscopia Mössbauer que es una técnica nuclear de análisis no destructivo basado en la emisión y absorción resonante de fotones $\gamma$ de 14.4 $\mathrm{keV}$ sin retroceso por un núcleo de ${ }^{57} \mathrm{Fe}$ diluido dentro de una matriz cubica de rodio. La absorción resonante puede ser observada como espectros característicos de cada muestra y puede dar información sobre el comportamiento magnético en nuestras muestras. Realizamos medidas de espectroscopia a diferentes temperaturas de la magnetita pura sintetizada por el primer método visto en la Figura. 7 y recubrimos su superficie con una capa de oro y quitosano cargando un fármaco de Piper regnelli (Miq.) como puede ser observado en la figura 8. En ambos casos puede ser observado un colapso del espectro a temperatura ambiente y espectros mejor resueltos a bajas temperaturas indicando efectos de relajación superparamagnética 
debido al tamaño pequeño de las partículas y en el otro caso cuando es recubierto con oro y quitosano cargando el fármaco la forma de línea de los espectros muestra un comportamiento diferente mostrando la influencia de los ligantes en los sítios del hierro que alteran la forma de línea a una forma tipo escalera. Los ajustes de los espectros a $4.2 \mathrm{~K}$ fueron realizados con el programa Normos Site que utiliza un ajuste por regresión no lineal para ajustar sextetos y en la tabla 1 observamos los parámetros Mössbauer a $4.2 \mathrm{~K}$ de la magnetita pura obtenidos después del ajuste preparada por el primer método y muestran la ocupación del hierro en los sitios tetrahedral (A) y octahedral [B] de la estructura cubica tipo espinela.

Tabla 1: Parámetros Mössbauer a $4.2 \mathrm{~K}$ de la magnetita pura preparada por el primer método.

\begin{tabular}{|ccc|}
\hline Sitios & IS (mm/s) & $\mathrm{B}_{\mathrm{hf}}(\mathrm{kOe})$ \\
(A) & 0.51 & 499 \\
[B] & 0.50 & 526 \\
\hline
\end{tabular}

Donde $\mathrm{IS}=$ corrimento isomerico, $\mathrm{B}_{\mathrm{hf}}=$ campo magnético hiperfino.

En la tabla 2 se muestran los parámetros Mössbauer de la magnetita preparada por el primer método recubierto con oro, quitosano y cargando un fármaco obtenido de las hojas de la planta Piper regnelli (Miq.).

Tabla 2: Parámetros Mössbauer a $4.2 \mathrm{~K}$ de la magnetita pura preparada por el primer método recubierta con oro cargando un fármaco.

$\begin{array}{ccc}\text { Sitios } & \text { IS }(\mathrm{mm} / \mathrm{s}) & \mathrm{B}_{\mathrm{hf}}(\mathrm{kOe}) \\ (\mathrm{A}) & 0.51 & 514 \\ {[\mathrm{~B}]} & 0.50 & 536\end{array}$

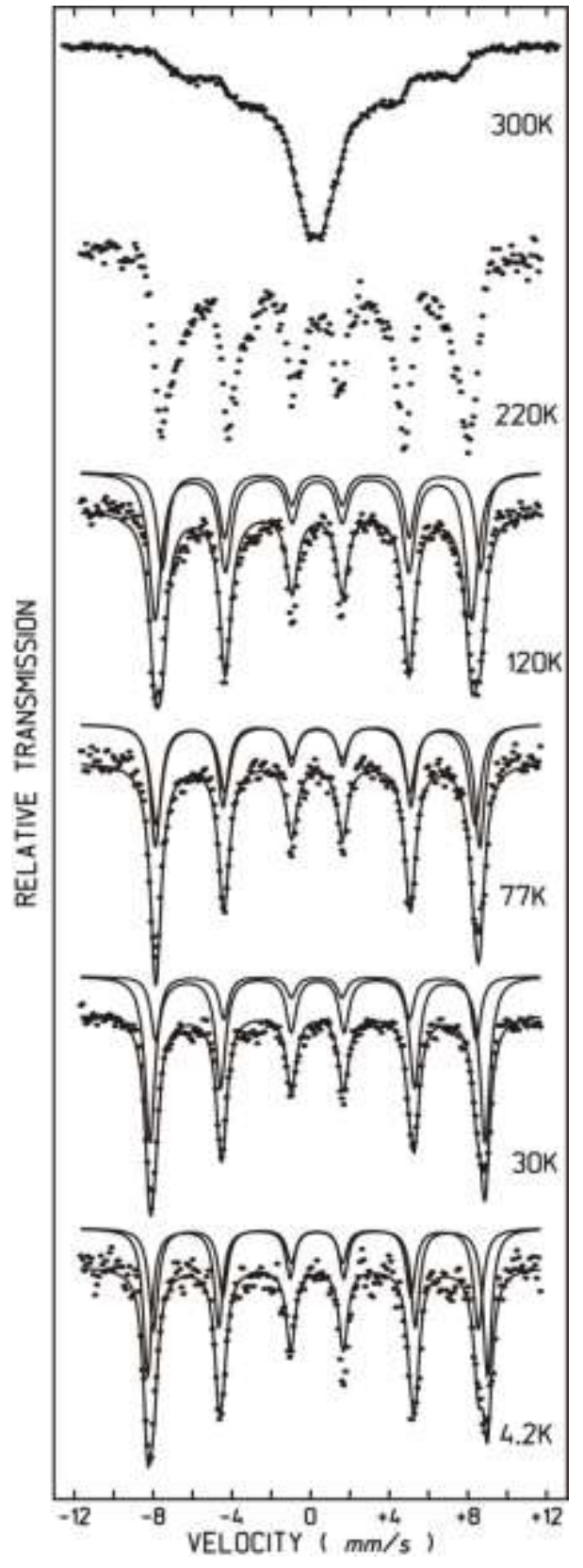

Figura 7: Espectro Mössbauer de la magnetita pura. 


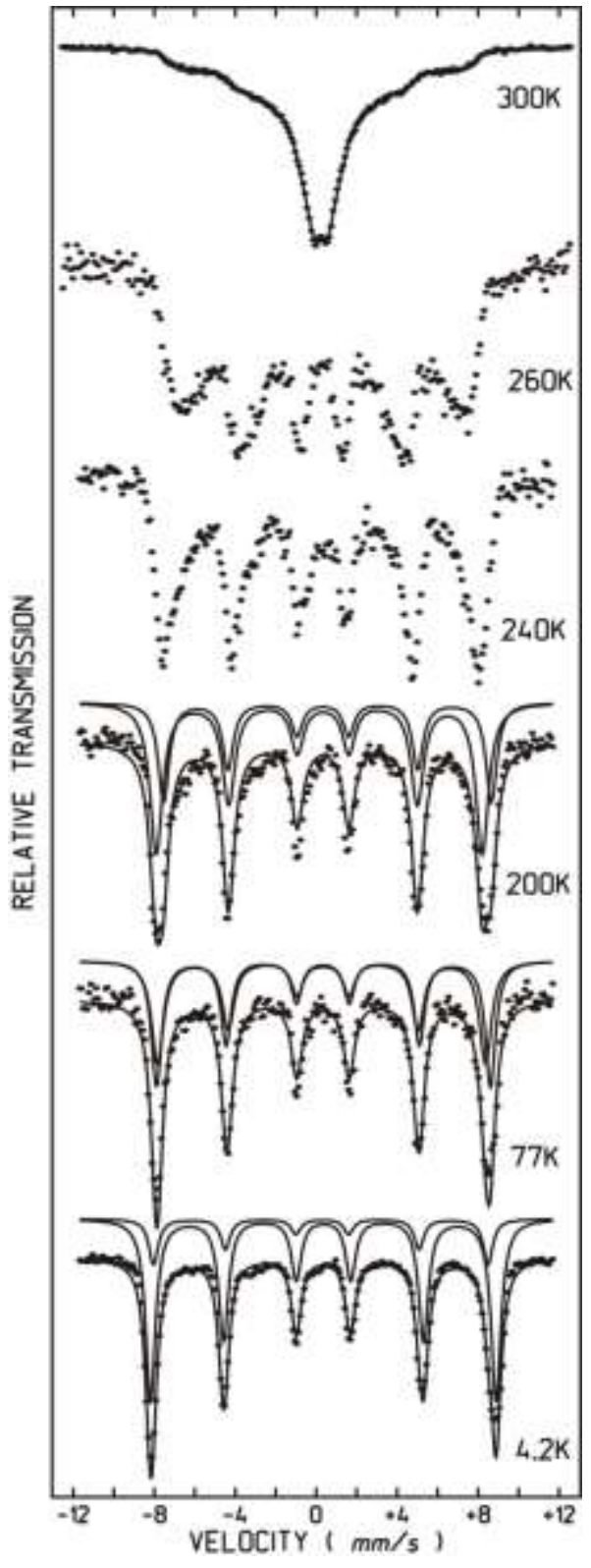

Figura 8: Espectro preparada por el primer método recubierta con oro cargando un fármaco

De la comparación de las dos tablas podemos decir que la simetría cubica no cambia y la densidad electrónica se mantiene constante. El campo magnético hiperfino experimenta un cambio debido a la funcionalización de las partículas magnéticas mostrando una relajación más rápida en comparación con el espectro de la magnetita pura. La Figura 9 muestra los espectros Mössbauer a diferentes temperaturas de la magnetita preparada con el tercer método de preparación funcionalizada con ácidos grasos obtenidos de la Mauritia flexuosa L. e quitosano. El espectro Mössbauer a $220 \mathrm{~K}$ muestra líneas anchas que corresponde a un comportamiento superparamagnético e a $4.2 \mathrm{~K}$ puede ser observado un espectro estático. El cambio en el ensanchamiento de las líneas estaría asociado al efecto de la funcionalización de las nanopartículas.

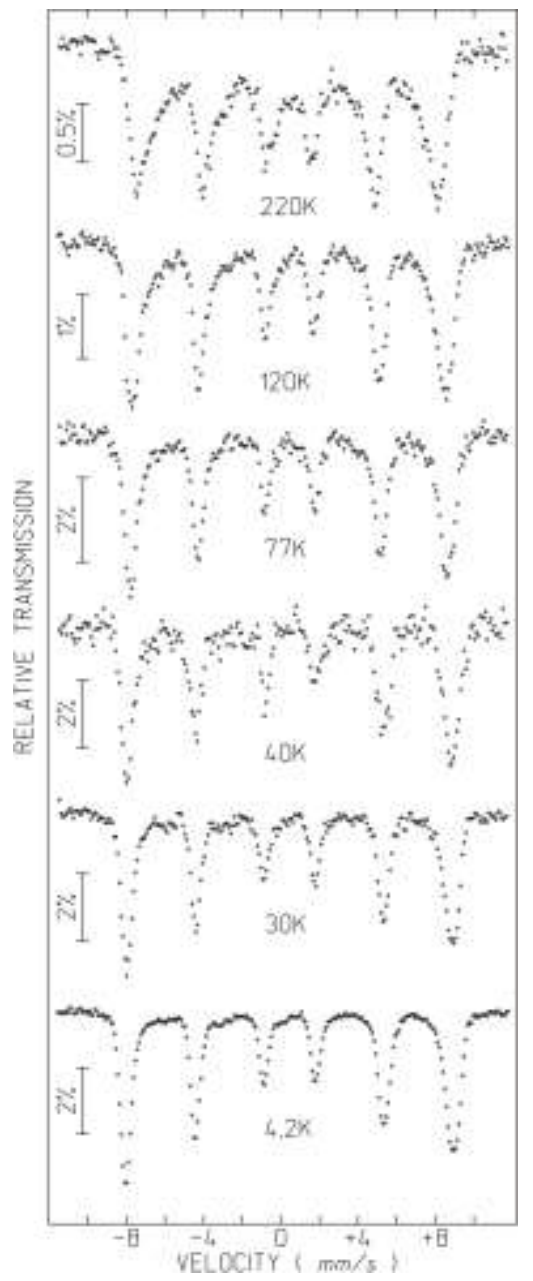

Figura 9: Espectro Mössbauer de la magnetita funcionalizada con ácidos grasos de Mauritia flexuosa $L$.

A $4.2 \mathrm{~K}$ el espectro fue ajustado con 2 subespectros magnéticos con parámetros: corrimiento isomérico (IS) y campo hiperfino magnético correspondientes a la posición del hierro en los sitios tetrahedral (A) e octahedral [B]. 1) IS $=0.50 \mathrm{~mm} / \mathrm{s}, \mathrm{H}_{\mathrm{hf}}=526 \mathrm{kOe}$ $\rightarrow$ sítio [B], 2) IS $=0.51 \mathrm{~mm} / \mathrm{s}, \mathrm{H}_{\mathrm{hf}}=499 \mathrm{kOe} \rightarrow$ sítio [A]. La Fig. 10 muestra los espectros Mössbauer a diferentes temperaturas de magnetita recubierta con oro y funcionalizada com os ácidos grasos de la Copaifera longsdorfii. El espectro Mössbauer a 120K muestra 2 líneas ensanchadas que corresponde a un comportamiento superparamagnético e a $4.2 \mathrm{~K}$ puede ser observado un espectro estático de seis líneas que corresponde a un comportamiento ferrimagnético. Para altas temperaturas se observa colapso dos sub-espectros magnéticos con un ensanchamiento de las líneas de forma asimétrica formando una combinación de sextetos y dobletes hasta transformarse en un doblete. La temperatura 
de bloqueo superparamagnético estaría próximo de $\mathrm{T}_{\mathrm{B}} \sim 100 \mathrm{~K}$. Ese cambio en la forma de línea estaría asociado con efectos del comportamiento superparamagnetico en nuestra muestra con una distribución de tamaños de partículas con diferentes barreras de energía de anisotropía y probablemente exista un desorden magnético en la superficie de las partículas.

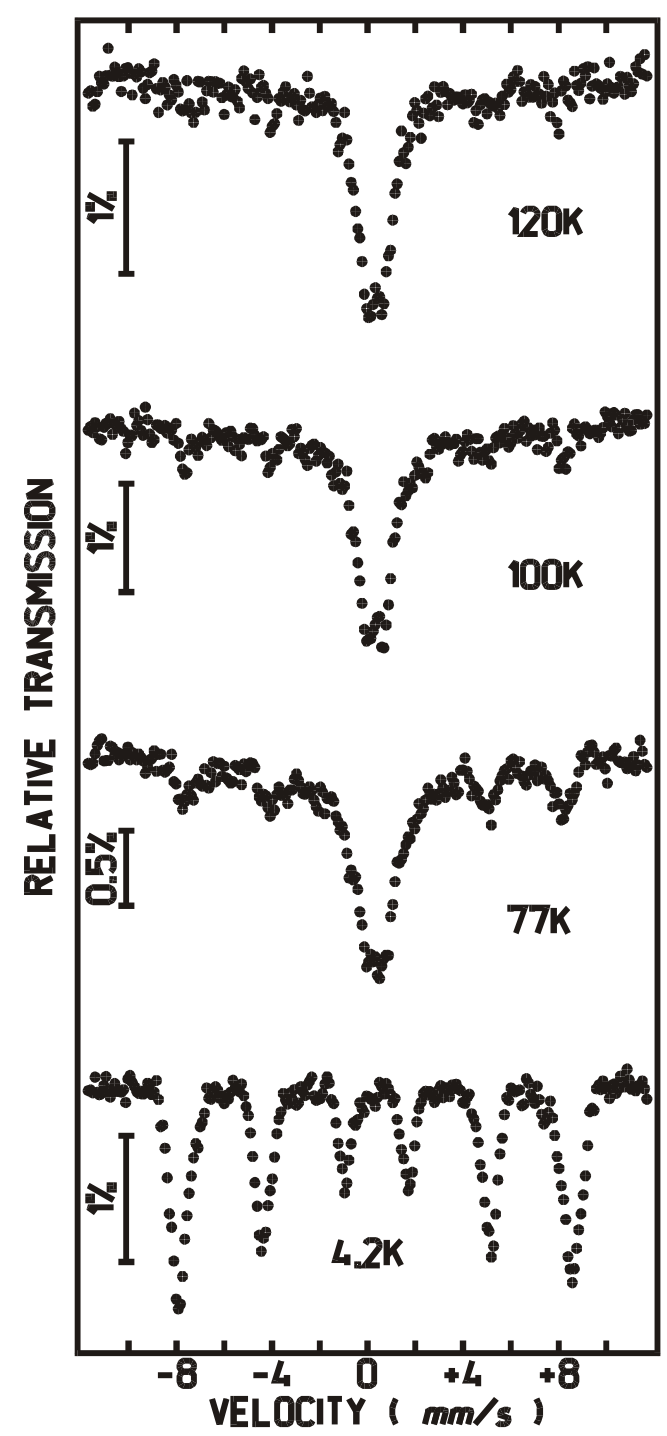

Figura 10: Espectro Mössbauer de la magnetita recubierta com oro y funcionalizada con ácidos grasos de Copaifera longsdorfii.

El ensanchamiento de la línea seria debido a una distribución de los sitios tetrahedral y octahedral y a una distribución e tamaños de partículas o puede estar asociada a la funcionalización de las nanopartículas. A $4.2 \mathrm{~K}$ el espectro Mössbauer fue ajustado con 2 subespectros magnéticos con parámetros: corrimiento isomérico (IS) y campo hiperfino magnético correspondientes a la posición del ion del hierro $\mathrm{Fe}^{3+}$ cúbico en los sitios tetrahedral (A) y octahedral [B]. 1) IS $=0.49 \mathrm{~mm} / \mathrm{s}, \mathrm{H}_{\mathrm{hf}}=520 \mathrm{kOe}$ $\rightarrow$ sitio [B], 2) IS $=0.50 \mathrm{~mm} / \mathrm{s}, \mathrm{H}_{\mathrm{hf}}=497 \mathrm{kOe} \rightarrow$ sitio [A]. La relajación superparamagnética en nuestras muestras está relacionada con la inversión térmicamente activada de la magnetización en partículas magnéticas de escala nanométrica. A bajas temperaturas, las ondas de spin son congeladas $\mathrm{y}$, de este modo, la magnetización es igual a la magnetización espontánea $\vec{M}$. A baja temperatura $T=4.2 \mathrm{~K}$ en la cual $T<\mathrm{T}_{\mathrm{B}}\left(\mathrm{T}_{\mathrm{B}}\right.$ es la temperatura de bloqueo superparamagnético abajo del cual las partículas son orientadas en la dirección del campo magnético aplicado), las nanopartículas exhiben un comportamiento ferrimagnético con una coercividad $\mathrm{H}_{\mathrm{c}}=600$ Oe y relación $\mathrm{M}_{\mathrm{r}} / \mathrm{M}_{\mathrm{s}}=0.8$ para la magnetita pura. La magnetización de saturación fue de $M_{s}=3 \mathrm{emu} / \mathrm{g}$ para las partículas con diámetro de $5 \mathrm{~nm}$, la cual fue obtenida a $4.2 \mathrm{~K}$ extrapolando la curva $M$ vs. $1 / \mathrm{H}$ cuando $1 / \mathrm{H} \rightarrow 0$. De la misma forma obtenemos $M_{s}=4$ emu/g para as partículas de $7 \mathrm{~nm}$ e $M_{s}=5.5 \mathrm{emu} / \mathrm{g}$ para las partículas de $10 \mathrm{~nm}$. La magnetización de todas nuestras muestras es mucho menor que la magnetización de partículas de magnetita de volumen mayor, por ejemplo, para partículas con un diámetro de $50 \mathrm{~nm}$ el valor de $M_{s}$ $(4.2 \mathrm{~K})=90 \mathrm{emu} / \mathrm{g}$, esto indicaría efectos de tamaño pequeño de partícula en nuestra muestra y efecto de la funcionalización de la superficie de nuestras partículas. La constante de anisotropía (K) calculada para nuestras muestras fue de $1.6 \times 10^{4}, 2 \times 10^{4} \mathrm{y}$ $2.3 \times 10^{4} \mathrm{~J} / \mathrm{m}^{3}$, para los tres tamaños de partículas de 5,7 y $10 \mathrm{~nm}$ sin funcionalización. Estos valores expresan una propiedad que determina la orientación preferencial fácil de la magnetización espontánea de nuestras partículas a lo largo de ciertas direcciones características.

\section{Conclusiones}

Fueron sintetizadas con éxito nanopartículas de magnetita no toxicas por tres procesos de síntesis química diferentes e su funcionalización con ácidos grasos obtenidos de los aceites de Copaifera longsdorfii y Mauritia flexuosa $L$ adicionando quitosano como agente complejante y cargando un fármaco obtenido de la planta Piper regnelli (Miq.) para tratamiento antitumoral. Los resultados de difracción de rayos $X$ mostraron que la magnetita es estequiométrica con tamaños de 5,7 y $10 \mathrm{~nm}$ para las muestras puras y funcionalizadas. La funcionalización no altero la estructura cristalina de nuestras muestras. Las imágenes de microscopia electrónica mostraron que las partículas tienen una distribución esférica. Los compuestos fueron estables durante un buen tiempo mostrando la eficiencia del método de preparación. Los espectros 
Mössbauer mostraron efectos de relajación superparamagnética indicando que son apropiados para ser usados como cargadores de fármacos.

\section{Referencias}

[1] S. Aksoy, N.A. Kalkan, E.A. Aksoy, N.J. Hasirce, J. Appl. Poly. Sc., 123 (2012)707716.

[2] A. A. Hashim (Editor.), InTech, Rijeka, Croatia, 2012.

[3] N.T.K. Thanh (Editor), Taylor \& Francis Group LLC; Boca Raton; FL, USA, 2012.
[4] J.T. Gordon, B.H. Reginald, TAN (Editor),; The Royal Society of Chemistry, Cambridge, UK, 2012.

[5] J. López, A.F. Ruiz, M. J. Nascimento Pontes, P.C. Morais, R.B. Azevedo, H.D. Pfannes, J.H. Dias Filho, AIP Conference Proceedings, Urs Häfeli (Editor), Canada (2010) 73-76.

E-mail: jorge0503@gmail.com 